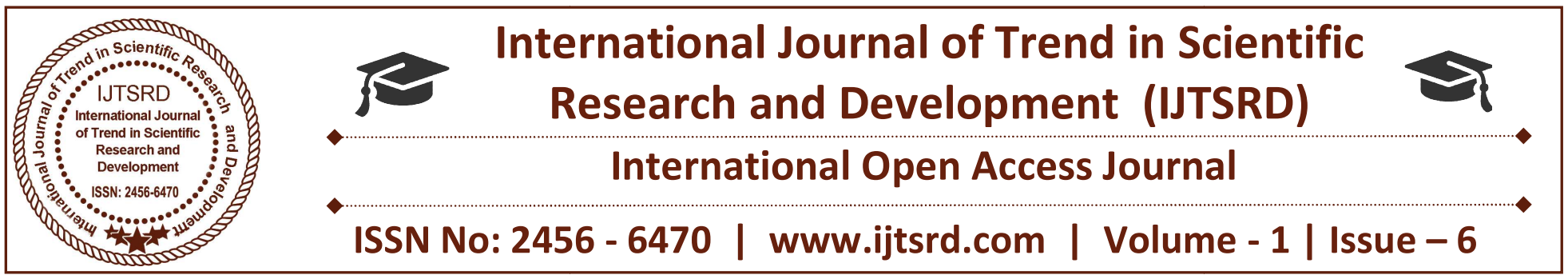

\title{
Circular Economy
}

\author{
K. M. Srisruthi \\ BBA. LLB.(Hons.), Saveetha School of Law, \\ Chennai, Tamil Nadu
}

\begin{abstract}
The article discusses about the "Circular Economy". A circular economy is a contrasting option to a linear economy (influence, use, to arrange) in which we keep assets being used for whatever length of time that conceivable, remove the most extreme incentive from them while being used, at that point recuperate and recover items and materials toward the finish of each administration life. The objective of this article is to know, some information about circular economy and to know about the companies that use circular economy. The article briefly says about the characteristics of a circular economy; the way of bringing circular economy and know some small and big industries that uses circular economy. The article also concluded by giving some best ways of using circular economy. The information for this article are gather from secondary sources.
\end{abstract}

\section{INTRODUCTION}

A roundabout economy is one that is helpful and regenerative by outline, and which means to keep items, parts and materials at their most astounding utility and incentive constantly, recognizing specialized and natural cycles.

\section{CHARACTERISTICS OF A CIRCULAR ECONOMY}

In a dubious and quick advancing world, the capacity to adjust to changing conditions is fundamental to flourish. Assorted variety can give this flexibility. Economies require an assorted scope of organizations of different scales, and associations require a scope of parts and abilities.

Squander is "planned out" - Squander does not exist. Items are composed and upgraded for dismantling and reuse. Organic material can be securely come back to the dirt.

Assorted variety constructs quality - In an indeterminate and quick developing world, the capacity to adjust to changing conditions is basic to flourish. Assorted variety can give this flexibility. Economies require a different scope of organizations of different scales, and associations require a scope of parts and abilities.

\section{Sustainable power sources control the economy}

Vitality required for a regenerative economy ought to be given by sustainable sources, diminishing asset reliance and expanding frameworks flexibility.

\section{Think in frameworks}

Some true components, for example, organizations, individuals or plants, are a piece of complex frameworks where diverse parts are firmly connected to each other, prompting some astonishing outcomes. Keeping in mind the end goal to deal with the economy well, these connections and results must be thought about consistently.

\section{Costs reflect genuine expenses}

Costs go about as messages, and consequently in a roundabout economy they have to reflect full expenses so as to be successful. 
International Journal of Trend in Scientific Research and Development (IJTSRD) ISSN: 2456-6470

\section{OBJECTIVES}

To know about circular economy

To know some companies that use circular economy

\section{CIRCULAR ECONOMY}

The Circular Economy: another mechanical insurgency is in progress. Around the globe, common assets are running out. Veolia utilizes waste to create new assets and add to a roundabout economy. In a traditional economy, everything is direct, from support to grave: extraction, creation and transfer. In the roundabout economy, utilization designs are intended to reflect the patterned approach of regular biological communities. Once utilized, all merchandise give results that can be reused in other assembling forms, making a righteous cycle more tuned in to the earth.

\section{Cases of arrangements we can utilize}

- Veolia reuses TVS and mobile phones in Angers, France

Rather than being hurled in the trash, these customer merchandise are dismantled and used to give new assets, for example, top notch polymers (plastics) reasonable for use as auxiliary crude materials to make new items, similar to these lavatory scales made by a main French maker of family unit apparatuses.

\section{- Rostock reuses 1 billion plastic jugs each year}

Consistently, 200 billion plastic jugs are made worldwide for juice, pop, family unit cleaning items and an entire scope of different employments. Veolia's treatment and reusing office in port of Rostock, northern Germany, reuses 1 billion plastic jugs a year. That is what might as well be called sparing 31,000 liters of raw petroleum.

\section{- Veolia has built the biggest slop treatment plant on the planet in Hong Kong}

This new plant is the biggest treatment muck cremation unit on the planet, on account of its introduced limit, with 2,000 tons treated every day by 110 individuals from faculty. The treatment and cremation innovation utilized decreases squander by $90 \%$, while ensuring the indigenous habitat and dispensing with ocean releases. Warmth and power are produced in ooze treatment, and utilized for the three spa pools found ideal beside the plant, and supply 4,000 families. A seawater desalination unit is utilized to cover site water necessities and 1,000 trees have been planted as a component of a carbon pay program.

\section{COMPANIES TO WATCH IN THE CIRCULAR ECONOMY}

At this point, most everybody meandering the domain of corporate maintainability has heard the expression "round economy" - perhaps a couple of a greater number of times than they'd want to review. Be that as it may, it's considerably more than simply one more trendy expression, as the roundabout economy can possibly take care of the world's mounting waste issue by getting rid of the very idea of waste out and out.

By making creation models that diminish dependence on crude materials through ceaselessly cycling materials of various types over into supply chains, organizations remain to pick up a business advantage by steeling themselves against fluctuating product markets and other future stuns.

While it makes long haul business and natural sense, changing from our present "take-make- squander" direct economy to a more "round" one that perspectives squander as specialized supplements isn't simple. Difficulties remain, including influencing the inner business to case for it, refreshing out of date open approaches to advance round systems and teaching purchasers about the benefits.

Be that as it may, the round economy is definitely not hypothetical - new companies and enormous organizations alike as of now are trying different things with the idea to manufacture new plans of action and brace existing ones.

In any case, the round economy is definitely not hypothetical - new companies and huge organizations alike as of now are trying different things with the idea to manufacture new plans of action and support existing ones. Here are eight of the most striking:

\section{New Companies}

\section{$>$ Thread}

This Pittsburgh-based Certified B Corporation changes plastic jugs from the avenues and waterways of Haiti and Honduras into "dependable texture" utilized as a part of buyer items. Notwithstanding lessening junk in Haiti and Honduras by making upcycled other options to 
squander, the organization additionally endeavors to give quality to local people in devastated groups.

String as of late cooperated with Timberland to give upcycled materials to use in the clothing brand's footwear. To include another level of straightforwardness, every yard of Thread texture is followed and followed at each progression of the upcycling procedure, from bottle accumulation to texture creation to the conveyance of the texture dart to the maker.

\section{$>$ Looptworks}

Propelled in 2009, Looptworks repurposes surrendered materials into "significant, enduring and constrained release items." By reusing the world's pre-buyer abundance, the Portland- based organization says it means to free the universe of waste while moving an era to diminish its effect on the planet. The line incorporates coats, hoodies, skirts, shirts and realistic T-shirts for the two men and ladies.

Having collaborated with Southwest Airlines in 2014 to upcycle its seat cowhide into soccer balls, sacks and different items, Looptworks proceeded with ahead a year ago with Alaska Airlines, transforming the aircraft's utilized seats into totes and totes. Looptworks gathers, sorts and cleans the seat materials, outlines and builds up the upcycled items, creates, markets and offers them.

\section{$>$ LanzaTech}

This firm applies roundabout financial standards to carbon by turning waste carbon from "an obligation to an open door," utilizing its protected organism innovation to change over carbon-rich squanders and buildups into important fuel and concoction items through a procedure of gas aging. LanzaTech targets carbon delivered by enterprises, for example, steel fabricating, oil refining and concoction creation, and additionally gasses produced by gasification of ranger service and agrarian deposits and city squander.

LanzaTech's procedure can be compared to a bottling works, the organization says, however rather than sugars and yeast to make lager, the organization utilizes microorganisms and waste gasses to make energizes and chemicals. The procedure catches and reuses squander gasses before they are radiated as nursery gasses, diminishing toxins and particulate discharges by more than 85 percent, while at the same time driving monetary development.

\section{Method}

While not precisely a startup any longer, Method is one of the biggest and quickest developing "green" cleaning items organizations in its field. The firm grasps round economy standards by utilizing unendingly recyclable materials, utilizing sustainable power source and support to-support confirmation. Items incorporate concentrated cleanser and its Ocean Plastic Bottle venture, utilizing disposed of plastic from the ocean to make its bundling.

\section{Huge Organisations}

\section{Dell}

In acknowledgment of the rising e-squander plague - fast innovation development and regularly shortening item life expectancies are added to about 42 million tons in 2014 - Dell is influencing a portion of the primary advances to a more "round" to production network. Toward the end of last year, the organization reported advance against its roundabout economy activities, including the extension of its shut circle reused plastic inventory network and the presentation of recovered carbon fiber source materials into some of its items. As a component of its 2020 Legacy of Good Plan, Dell likewise has set up two goals secured to cutting on e-squander: utilizing 50 million pounds of reused materials and recuperating 2 billion pounds of e-squander by 2020 .

\section{$>$ Levi Strauss}

With around 24 billion pounds of attire, shoes and materials finding their way into U.S. landfills every year - including untold huge amounts of pants Levi's is chipping away at some intriguing short-and long haul roundabout economy activities went for removing a piece from this measurement. Each Levi's store acknowledges old garments and shoes of any brand, which the organization gathers and repurposes or reuses with its accomplice, I:CO. The gathered garments are changed into things, for example, protection for structures, padding material and new filaments for dress.

The gathered garments are changed into things, for example, protection for structures, padding material and new filaments for dress. 
In the interim, Levi's is attempting to set up a foundation that backings shut circle items by 2020. In the long run, the organization plans to have the capacity to reuse old Levi's pants into new ones.

\section{Timberland}

Timberland and tire maker and merchant Omni United have collaborated to deliver a line of tires intended to be reused into footwear outsoles once they achieve end-of-life out and about. With the tire and footwear enterprises being two of the biggest clients of virgin elastic, this coordinated effort guarantees that less tires are utilized for fuel or wind up in landfill through another tire return chain of care process.

Here's the means by which the procedure works: Worn out Timberland Tires are put aside to recycle by tire retailers once shoppers have bought substitutions; these tires are then transported to a North American reusing office to be transformed into morsel elastic; this piece elastic is handled into sheet elastic prepared to be delivered to Timberland outsole makers; the sheet elastic is blended into a compound for outsoles to be consolidated into Timberland boots and shoes.

\section{Energizer}

Batteries are hard to reuse, on account of their confused science making them be named unsafe materials. That is the reason around 180,000 tons of batteries wind up in U.S. landfills every year. At present, most batteries are "downcycled" into materials for street development and landfill tops yet these commonly are "one and done" sort manages restricted esteem.

Energizer is making a portion of the primary advances into applying round monetary standards to its batteries; having delivered Eco Advanced - the world's first battery made with 4 percent reused batteries. While this won't not seem like a great figure, it took the organization eight years to accomplish it. Being the first to endeavor to catch these materials to fill in as contributions to new batteries carried with it challenges related with building up another inventory network, and setting up coordinations with new waste items.

\section{CONCLUSION}

The circular economy is and will keep on being a clumsy term. It is not another model. It principally concerns organizing the economy reasonably with the need being to utilize materials productively and decrease and at last dispense with squander streams. The materials cycle is the focal issue.

In this uncommon, we began by demonstrating that this approach could prompt extremely positive and supportable income models. Yet additionally that these plans of action would not really add to expanded success in macroeconomic terms.

Besides, we demonstrated that our economy, yet too gradually maybe, is gaining more prominent ground towards circularity as far as generation than as far as utilization. The Dutch economy scores profoundly as far as materials effectiveness, and the utilization of materials, while still high, is lessening. Things are less ruddy with regards to utilization. We devour a considerable measure of imported products with a generally huge biological impression. A roundabout economy at home does little to improve this. 